\title{
PLANT DIVERSITY AND PHYLOGENETIC COMMUNITY STRUCTURE ALONG ENVIRONMENTAL GRADIENTS IN A TEMPERATE FOREST, SOUTH KOREA
}

\author{
Hyungho Kim ${ }^{1}$ Jung-Hwa Chun ${ }^{2}$ and Chang-Bae Lee ${ }^{3 *}$
}

${ }^{1}$ Department of Forest Environmental Sciences, Gyeongsang National University (Institute of Agricultural and Life Science), Jinjudaero 501, Jinju 52828, Republic of Korea, ${ }^{2}$ Research Planning and Coordination Division, National Institute of Forest Science, 57 Hoegiro, Dongdaemungu, Seoul 02455, Republic of Korea, ${ }^{3}$ Department of Forestry, Environment and Systems (Creative Convergence Forest Science Specialist Training Center), Kookmin University, 77 Jeongneungro, Seongbukgu, Seoul 02707, Republic of Korea

*Corresponding Author's E-mail: kecolee@kookmin.ac.kr

\begin{abstract}
Recently, species-centric approach in biodiversity research have been complemented by phylogenetic approach to reflect evolutionary history of species and to improve our understanding of community assembly processes in plant communities. However, the study on species and phylogenetic diversity along environmental gradients and the drivers are very rare. In this context, the present study examined species, phylogenetic diversity and phylogenetic community structures for vascular plants along two elevation transects on the Mt. Seorak, South Korea, in 2011. We calculated species richness and Faith's phylogenetic diversity as diversity indices and net relatedness index as a phylogenetic community structure index using vegetation data from 130 plots with $400 \mathrm{~m}^{2}$ in the size of each plot. We also evaluated the effects of climatic and topographic factors on the diversity patterns using multi-model inference and variation partitioning. From the results of linear regression analysis, Species richness and phylogenetic diversity have no relationship with elevation along all the study transect. However, the main factors to control these diversity patterns on the two transects were topographic factors. In addition, phylogenetic community structures showed phylogenetic overdispersion and clustering depending on the study transects, which are explained as results of biotic interactions and environmental filtering by climatic and topographic factors. These results indicate that niche-based deterministic processes such as environmental filtering and interspecific interaction may be predominant in structuring community assembly of vascular plants along local elevation gradients.
\end{abstract}

Key words: Climatic Factor, Plant Diversity, Community Structure, Elevation, Topographic Factor.

https://doi.org/10.36899/JAPS.2020.4.0112

Published online April 25, 2020

\section{INTRODUCTION}

Understanding of regional and local variations in species diversity and the distribution was an important issue in ecology and biogeography (Gaston, 2000) because this is essential knowledge for the conservation and sustainability of biodiversity (Grytnes and Vetaas, 2002; Storch et al., 2006; Sharma et al., 2019). In recent decades, researches on the patterns of species distribution and the determinants across environmental gradients such as latitude and elevation have been a very popular filed in ecology and biogeography (Grau et al., 2007; Kluge and Kessler, 2011; Lee et al., 2013). Especially, many ecologists recognize mountainous ecosystems are a remarkable and unique system to evaluate ecological theory and the processes (Gaston, 2000; Grau et al., 2007). The elevation naturally formed in the mountains is a physically important inherent factor for biological distribution patterns (Rahbek, 2005). Especially, elevation affects to climatic factors which control the ecophysiological adaptation of organisms including mammals (Rowe, 2009), birds (McCain, 2009), invertebrates (Liew et al., 2010) and plants (Grytnes et al., 2006). Many earlier studies explored the distribution of species diversity along elevations and documented different patterns in many regions and taxa (Rahbek, 2005). Of these patterns, it is recognized that monotonic decline and hump-shaped patterns of species diversity across elevation gradients are most common (Rahbek, 2005).

Previous studies on elevational diversity patterns mostly focused on species richness, however, this species-centric approaches treat that all species is evolutionarily and ecologically independent. Moreover, this approach has problems that may not reflect information on the mechanisms driving evolutionary and functional trajectories (Webb et al., 2002). In recent, to complement the shortcomings of these species-centric approaches, community phylogenetics as a new alternative approach was introduced to improve our knowledge of the mechanism underlying the formation and change of biodiversity. Especially, many ecologists started to use the new method to add meaningful insights into researches on community ecology and evolution. 
They differentiated the relative importance of deterministic and stochastic processes in structuring community assembly in various taxa and regions (Kluge and Kessler, 2011; Dreiss et al., 2015; Zhou et al., 2018). First, deterministic process mentioned that niche-based drivers such as habitat filtering and interspecfic competition play a pivotal role in structuring the species assemblages in local communities and induce different community assemblies among various environmental conditions (Cadotte et al., 2011; Swenson, 2011). For example, if the environmental filtering is the main determinant of community assembly, species with specific traits are filtered to enhance survival, growth and reproduction in specific environments and co-occurring species within an assemblage should be more phylogenetically related (i.e., phylogenetic clustering). However, if species interactions such as competition drive the community assembly, a species should compete with other species and lead to phylogenetically distant assemblages (Webb et al., 2002; Yang et al., 2015; Worthy et al., 2019). In contrast, stochastic process focuses on the role of accidental events such as dispersal limitation, disturbance and local extinction in shaping species assemblages in local communities and the process causes random species composition among local communities (Kembel and Hubbell, 2006).

Although there were several studies on phylogenetic community structures and their mechanisms in community assemblies along environmental gradients in various regions (Kluge and Kessler, 2011; Dreiss et al., 2015; Shooner et al., 2018), there are still few studies to investigate the patterns of plant community structure in phylogenetic insights and the underlying mechanisms along elevational gradients. Moreover, these previous studies focused to explain phylogenetic structures and patterns along large and broad elevation gradients such as regional and continental scales and did not explore the patterns and structures at smaller scales such as a local slope. However, spatial scales can drive different biodiversity patterns (Jetz and Rahbek, 2002) and thus it is distinctly a need to such small local-scale structures and patterns (Rahbek, 2005; Chun and Lee, 2013; Chun and Lee, 2018).

Under these contexts, the main purposes of this study are 1) to examine and compare the diversity patterns and community phylogenetic structures in vascular plant assemblages along two elevation transects on the Mt. Seorak, South Korea, 2) to assess the relative contributions of climatic factors including six temperateand precipitation-related factors and topographic factors such as topographic position index (TPI), surface area ratio (SAR), slope and rocky area ratio (RAR) on diversity patterns and community structures and lastly 3 ) to evaluate which mechanism between deterministic and stochastic processes is the major driver in shaping community structures of vascular plants.

\section{MATERIALS AND METHODS}

Study area and vegetation survey: The present study was implemented from May to July in 2011 along two elevation transects on the Mt. Seorak $\left(38^{\circ} 00^{\prime}-38^{\circ} 15^{\prime} \mathrm{N}\right.$, $128^{\circ} 10^{\prime}-128^{\circ} 40^{\prime} \mathrm{E}$ ), South Korea (Fig. 1). The Mt. Seorak is the third-highest mountain in South Korea. Korean government and UNESCO designated the Mt. Seorak as a nature reserve in 1965 and a biosphere reserve in 1982, respectively. The area of mountain is $163.6 \mathrm{~km}^{2}$ and the highest peak, Daechungbong, exceeds $1700 \mathrm{~m}$ above sea level (a.s.l.). The mountain contains gneiss and dissected granite and is characterized by steed ridges and rocky areas. The annual mean precipitation and temperature approximately are $1340 \mathrm{~mm}$ and $13^{\circ} \mathrm{C}$, respectively (Chun and Lee, 2013). More than 1000 plant species have been documented in the mountain (Kong, 2007). The vegetation communities along elevation gradients on the mountain is mainly divided into four vegetation types by dominant tree species (Kong, 2007), as follows: (1) pine and temperate deciduous forest dominated by Pinus densiflora Siebold \& Zucc. and Rhododendron mucronulatum D.Don ex G.Don under $<500 \mathrm{~m}$ a.s.l.; (2) coniferous and temperate deciduous mixed forest dominated by $P$. koraiensis Siebold \& Zucc., Abies holophylla Maxim., Quercus mongolica Fisch. ex Ledeb., Betula schmidtii Regel and Magnolia sieboldii K. Koch between 500-1100 m a.s.l.; (3) subalpine coniferous forest between 1100-1500 m a.s.l. dominated by Taxus cuspidate Siebold \& Zucc., Thuja koraiensis Nakai, and A. nephrolepis (Trautv.) Maxim.; and (4) alpine forest dominated by P. pumila (Pall.) Regel and $R$. mucronulatum var. ciliatum Nakai. over 1500 m a.s.l. (Kong, 2007).

For vegetation sampling, two transects with 100-m-width along elevation gradients were installed using Osaek and Namgyori trails to Daechungbong on the mountain. The lengths of the Osaek and Namgyori trails are about $5.3 \mathrm{~km}$ and $22.4 \mathrm{~km}$, respectively. We randomly established five plots every $100 \mathrm{~m}$ interval along the two transect and the area of each plot was $400 \mathrm{~m}^{2}$. Plant species and coverage-based abundance with BraunBlanquet's method (1965) were recorded in each plot. Vegetation data was collected from 60 plots for the Osaek transect and 70 plots for the Namgyori transect in the Mt. Seorak. We observed a total of 235 plant species from 130 plots along the two transects. A total of 135 species were herbaceous plants $(57 \%)$, and woody species were 100 species (43\%). A total of 164 and 211 plant species were recorded along the Osaek and Namgyori transects, respectively.

Phylogenetic tree construction: Phylogenetic super-tree containing all vascular plants recorded from field survey was generated by the plant phylogeny database Phylomatic (Webb and Donoghue, 2005). The 
Phylomatic uses the consensus tree (R20120829) from Angiosperm Phylogeny Group III (APG III) as a backbone. BLADJ (branch length adjustment) algorithm used for the assignment of branch length in the free software Phylocom 4.2 (Webb et al., 2008) to constrain the internal nodes with available age estimates from Wikstrom et al. (2001) and interpolated the other nodes for which direct age estimates are not available (Bryant et al., 2008). The constructed phylogenetic tree was used to calculate phylogenetic community structure for the two transects (Fig. 2).

Diversity and phylogenetic community structure: We used species richness (i.e., number of species) in a plot as a proxy of species diversity. Phylogenetic diversity in a plot was calculated using Faith's phylogenetic diversity (PD). PD is calculated as the total branch lengths of all the species in a plot using the constructed phylgenetic tree (Faith, 1992). Abundance weighted net relatedness index (NRI) among co-existing species in a plot was also calculated to measure the magnitude of phylogenetic clustering using Phylocom 4.2 (Webb et al., 2008). The NRI was calculated as:

$$
N R=\frac{-1 \times(M \quad \text { sample }-M \quad \text { random })}{S \text { random }}
$$

where $\mathrm{MPD}_{\text {sample }}$ indicates the mean value of pairwise phylogenetic distance between all the species in a plot. The $\mathrm{MPD}_{\text {random }}$ and $\mathrm{SD}_{\text {random }}$ are the mean MPD and standard deviation of MPD from 1000 randomly generated null models. Here, MDP emphasizes the deep phylogenetic structure in a phylogeny and MDP is thought to have tree-wide sensitive patterns of phylogenetic overdispersion than to the structure near the terminals (Webb et al., 2002). As the deeper parts of the phylogeny used are well supported, coming from APG III classification, there should not be any important bias in NRI measurements caused by the limited tip resolution in the phylogeny used (Swenson, 2011). And we used random shuffling null model based alteration of specie names across the terminals in phylogenetic tree. This model randomly generates the phylogenetic relatedness of species to one another, while maintain the observed plant community matrix. Therefore, this model maintains the observed levels of spatial distribution and number of species and abundance in each randomization (Swenson et al., 2012).

Environmental factors: We included climatic factors in a plot with digital climate maps produced by the Korea Meteorological Agency such as annual mean temperature, temperature in January (the coldest month), temperature in August (the hottest month), temperature of growing season (generally May to August), annual mean precipitation and precipitation of growing season (Chun and Lee, 2013). The spatial resolutions were $270 \mathrm{~m}$ and $30 \mathrm{~m}$ for precipitation- and temperature-related factors, respectively. And climate data were from 1971 to 2008 and from 1981 to 2009 for temperate- and precipitationrelated data, respectively. The log-transformation was used for two precipitation-related factors to attain normality for further analysis.

We also used topographic factors such as slope, RAR, TPI and SAR in each plot. Although soil chemical and physical properties such as nutrient and moisture contents often are employed as proxies of habitat factors in previous studies (Moeslund et al., 2013), these topographic factors in this study was used because Mt. Seorak contains many rocky areas and various terrains and thus the collection of soil samples is mostly impossible in the mountain. Many vascular plants in the mountain do not inhabit in such steep and rocky locations (Kong, 2007). Therefore, we judged these factors will be more crucial to the growth and existence of plants than other habitat factors. Slopes from the four corners and the center of a plot using an inclinometer were measured and the mean value of slopes measured in a plot was used. For the calculation of RAR, four lines penetrative the center of the plot were established and divided the lines into segments of 1-m length. And then we quantified the ratio of substrates including rock and soil intercepting a segment. The proportion of rock substrates intercepting 200 segments in a plot was identified as RAR. Slope and RAR were log-transformed and arcsine square root transformed for further analysis, respectively. The other two topographic factors such as TPI and SAR were calculated for each plot using a triangular irregular network model using the digital elevation model (DEM) with a $1: 25,000$ digital terrain map. SAR is a method to calculate rugosity (i.e., a type of roughness). The rugosity represents basically the ratio of surface area to the planar area (Jenness, 2004). TPI is calculated as the topographic position relative to the surrounding locations. The negative and positive values indicates ravines and ridges, respectively (De Reu et al., 2013). DEM with 30-m resolution was used for calculation of TPI and SAR with ArcGIS.

To reduce the number of factors and covariation and possible redundancy in environmental variable data, two separate principal component analysis (PCA) were performed on each set of climatic and topographic factors (Table 1). As new climatic factors, the first two PCA axes were used that is retained 96.1\% of the total variation from the original factors. The PCAderived climatic factors were named $\mathrm{PC} 1_{\text {clim }}$ and $\mathrm{PC} 2_{\text {clim. }}$. And the first three PCA axes were used as new topographic factors that is retained $91.7 \%$ of the total variation from the original factors. The PCA-derived topographic factors were named $\mathrm{PC}_{\text {topo }}, \mathrm{PC}_{\text {topo }}$ and PC 3 topo.

Statistical analysis: Pearson correlation coefficient was used to examine the relationship between species richness and PD. Simple linear regression analysis was employed 
to examine the relationships between elevation and species richness, PD and NRI. And simple ordinary least squares (OLS) models were performed to explore the effects of each factor such as $\mathrm{PC} 1_{\text {clim }}, \mathrm{PC} 2_{\text {clim }}, \mathrm{PC} 1_{\text {topo, }}$, $\mathrm{PC} 2_{\text {topo }}$ and $\mathrm{PC} 3_{\text {topo }}$ on diversity and community structure indices. Simple conditional autoregressive (CAR) analysis was also used in addition to simple OLS models. Recent papers recommend autoregressive analyses because the models can exclude the estimates of invalid parameter and inflation of type I errors caused by spatial autocorrelation (Jetz and Rahbek, 2002). Multi-model inference with model averaging approach was also used to evaluate the relative contribution of environmental factors controlling patterns of species and phylogenetic diversity and phylogenetic community structure, respectively. Model averaging simultaneously examines several combinations to seek the best model set using the Akaike's information criterion (Legendre, 1993; Burnham and Anderson, 2002). This approach quantifies the relative contribution of each explanatory factor with summation of the Akaike weights across all possible models. Moreover, studies focusing on mechanisms driving diversity distribution commonly use multiple regressions-related statistical models (Diniz-Filho et al., 2003). We also employed variation partitioning with partial regression (Legendre and Legendre, 1998) with the five factors divided into two factors, climatic $\left(\mathrm{PC} 1_{\text {clim }}\right.$ and $\left.\mathrm{PC} 2_{\text {clim }}\right)$ and topographic $\left(\mathrm{PC}_{\text {topo }}, \mathrm{PC}_{\text {topo }}\right.$ and $\mathrm{PC} 3_{\text {topo }}$ ) factors to separate and compare the explanatory power of the new factors. PAST 2.17 and SAM 4.0 was used for statistical analyses in this study.

\section{RESULTS}

From the results of PCA with six climatic factors (Table 1), $\mathrm{PC} 1_{\text {clim }}$ had positive correlation with four temperature-related factors and $\mathrm{PC} 22_{\text {clim }}$ was correlated with two precipitation-related factors. $\mathrm{PC} 1_{\text {topo }}$ had positive correlation with slope and SAR. PC 2 topo was correlated with RAR and TPI and PC $3_{\text {topo had an }}$ important relationship with TPI. These results indicate that $\mathrm{PC} 1_{\text {clim }}, \mathrm{PC} 2_{\text {clim }}$ are temperature- and precipitationrelated climatic factors, respectively. Although it is difficult to clearly distinguish topographic factors, $\mathrm{PC} 1_{\text {topo }}$, $\mathrm{PC} 2_{\text {topo }}$ and $\mathrm{PC} 3_{\text {topo }}$ are slope-, rocky- and TPI-related topographic factors, respectively.

In elevational diversity patterns, although species richness and PD along the Osaek transect decrease with increasing elevation (Fig. 3a and c), the relationships were statistically not significant $(P>0.05)$. Species richness and PD along the Namgyori transect also showed not significant relationships with increasing elevation (Fig. 3b and d). The patterns of NRIs as a measurement of phylogenetic community structure showed negative and positive correlations with increasing elevation for the Osaek and Namgyori transects, respectively (Fig. 3e and f). And species richness and PD had strong linear relationships along the two transects (Fig. 4a and b), whereas species richness did not show significant relationships with NRI (Fig. 4c-f). This result indicates that species richness can be used a substitute of PD but not the index of phylogenetic community structure such as NRI.

Based on simple OLS models, species richness and PD of vascular plants were significantly predicted by $\mathrm{PC}_{3}$ topo and $\mathrm{PC}_{1}$ topo along the Osaek and Namgyori transects, respectively (Table 2). These results indicate that topographic factors are more important than climatic factors for species richness and PD on the both transects. $P C 1_{\text {clim }}$ was the most important variable to explain the pattern of NRI along the Osaek transect, whereas three environmental factors such as $\mathrm{PC} 2_{\text {clim, }} \mathrm{PC} 1_{\text {topo }}$ and $\mathrm{PC} 2_{\text {topo }}$ were important as predictors for NRI along the Namgyori transect. The results of simple CAR models were similar to those of simple OLS models (Table 2). These results represent that the influence of spatial autocorrelation for the patterns of diversity along the elevation gradients is not significant in the study transects. The results of multi-model inference also were similar to those of simple OLS and CAR models although there were some exceptions for species richness and PD on the Namgyori transect and NRI on the Osaek transect (Table 3). That is, $\mathrm{PC} 1_{\text {topo }}$ and $\mathrm{PC} 3_{\text {topo }}$ were important for predicting species richness and all the topographic factors (i.e., $\mathrm{PC} 1_{\text {topo }}, \mathrm{PC} 2_{\text {topo }}$ and $\mathrm{PC} 3_{\text {topo }}$ ) were important for $\mathrm{PD}$ along the Namgyori transect. Climatic factors such as $\mathrm{PC} 1_{\text {clim }}$ and $\mathrm{PC} 2_{\text {clim }}$ were significant predictors for the pattern of NRI along the Osaek transect. Moreover, the results of variation partitioning also re-emphasized those of the multi-model inference (Fig. 5). The pure effects of topographic factors were higher than those of climatic factors for species richness and PD of vascular plants along the study transects, whereas climatic factors had higher pure effects than topographic factors for NRI as a phylogenetic community structure index.

Table 1. Results of two separate principal component (PC) analyses with six climatic and four topographic factors for the two study transects on the Mt. Seorak.

\begin{tabular}{|c|c|c|c|c|c|c|}
\hline Climatic factors & PC1 & PC2 & PC3 & PC4 & PC5 & PC6 \\
\hline Explained variance (\%) & 88.36 & 7.82 & 3.67 & 0.11 & 0.04 & $<0.01$ \\
\hline Loadings & & & & & & \\
\hline Mean annual temperature & 0.42 & 0.30 & -0.06 & 0.12 & -0.22 & -0.82 \\
\hline
\end{tabular}




\begin{tabular}{lcccccc}
\hline Mean temperature in January (the coldest month) & 0.39 & 0.30 & -0.78 & -0.12 & 0.20 & 0.30 \\
Mean temperature in August (the hottest month) & 0.42 & 0.22 & 0.53 & -0.26 & 0.66 & 0.05 \\
Mean temperature from May to August (growing season) & 0.42 & 0.29 & 0.33 & 0.31 & -0.54 & 0.49 \\
Mean annual precipitation & -0.39 & 0.63 & 0.07 & -0.61 & -0.27 & 0.01 \\
$\quad$ Mean precipitation of growing season & -0.40 & 0.54 & -0.01 & 0.66 & 0.34 & -0.01 \\
Topographic factors & & & & & \\
Explained variance (\%) & 41.78 & 26.25 & 23.65 & 8.32 & - \\
$\quad$ Loadings & & & & - \\
Slope & 0.70 & -0.12 & -0.12 & -0.70 & - \\
Rocky area ratio & 0.26 & 0.67 & -0.65 & 0.26 & - & - \\
Topographic position index & 0.14 & 0.68 & 0.71 & -0.11 & - & - \\
Surface area ratio & 0.66 & -0.27 & 0.24 & 0.66 & - & - \\
\hline
\end{tabular}

Table 2. Coefficient of determination $\left(\mathrm{R}^{2}\right)$ and significance level from simple ordinary least squares (OLS) and conditional autoregressive (CAR) models for environmental factors and the indices of plant diversity and community structure along the study transects on the Mt. Seorak, South Korea.

\begin{tabular}{|c|c|c|c|c|c|c|c|c|c|c|c|}
\hline \multirow{2}{*}{ Study transect } & \multirow{2}{*}{ Index } & \multicolumn{5}{|c|}{ OLS model } & \multicolumn{5}{|c|}{ CAR model } \\
\hline & & PC1 $_{\text {climate }}$ & PC2 $2_{\text {climate }}$ & $\mathbf{P C 1}_{\text {topo }}$ & PC2 topo & PC3 $3_{\text {topo }}$ & $\mathbf{P C 1}_{\text {climate }}$ & PC2 $2_{\text {climate }}$ & PC1 $_{\text {topo }}$ & PC2 $2_{\text {topo }}$ & $\mathbf{P C 3}_{\text {tope }}$ \\
\hline \multirow[t]{3}{*}{ Osaek } & SR & 0.01 & 0.02 & $<0.01$ & $<0.01$ & $0.13^{* *}$ & 0.01 & 0.01 & $<0.01$ & $<0.01$ & $0.13^{* *}$ \\
\hline & PD & $<0.01$ & 0.02 & $<0.01$ & $<0.01$ & $0.11^{* *}$ & $<0.01$ & 0.01 & $<0.01$ & $<0.01$ & $0.11^{* *}$ \\
\hline & NRI & $0.29^{* * *}$ & 0.04 & $<0.01$ & $<0.01$ & $<0.01$ & $0.28^{* * *}$ & 0.04 & $<0.01$ & $<0.01$ & $<0.01$ \\
\hline \multirow[t]{3}{*}{ Namgyori } & SR & $<0.01$ & 0.03 & $0.10^{*}$ & 0.02 & 0.04 & $<0.01$ & 0.03 & $0.10^{*}$ & 0.01 & 0.04 \\
\hline & PD & $<0.01$ & 0.03 & $0.08^{*}$ & 0.03 & 0.02 & $<0.01$ & 0.03 & $0.07^{*}$ & 0.02 & 0.02 \\
\hline & NRI & 0.02 & $0.14^{* *}$ & $0.08^{*}$ & $0.07^{*}$ & 0.02 & $<0.01$ & $0.13^{* *}$ & $0.07^{*}$ & $0.06^{*}$ & 0.02 \\
\hline
\end{tabular}

Significance levels are ${ }^{*} p<0.05 ;{ }^{* *} p<0.01 ;{ }^{* * *} p<0.001$

Table 3. Beta coefficient and importance value of each variable based on multi-model inference in determining plant diversity and phylogenetic community structure indices along the study transects.

\begin{tabular}{|c|c|c|c|c|c|c|c|}
\hline \multirow{2}{*}{$\begin{array}{l}\text { Study } \\
\text { transect }\end{array}$} & \multirow[b]{2}{*}{ Variable } & \multicolumn{2}{|c|}{ Species richness } & \multicolumn{2}{|c|}{ Phylogenetic diversity } & \multicolumn{2}{|c|}{ Net relatedness index } \\
\hline & & $\begin{array}{c}\text { Beta } \\
\text { coefficient }\end{array}$ & $\begin{array}{c}\text { Importance } \\
\text { value }\end{array}$ & $\begin{array}{c}\text { Beta } \\
\text { coefficient }\end{array}$ & $\begin{array}{c}\text { Importance } \\
\text { value }\end{array}$ & $\begin{array}{c}\text { Beta } \\
\text { coefficient }\end{array}$ & $\begin{array}{c}\text { Importance } \\
\text { value }\end{array}$ \\
\hline \multirow{5}{*}{ Osaek } & $\mathrm{PC}_{\text {clim }}$ & 0.145 & 0.384 & 0.092 & 0.295 & $0.566^{*}$ & $1^{*}$ \\
\hline & $\mathrm{PC} 2$ clim & -0.075 & 0.271 & -0.109 & 0.309 & $-0.246^{*}$ & $0.772^{*}$ \\
\hline & $\mathrm{PC}_{\text {topo }}$ & 0.092 & 0.289 & 0.091 & 0.29 & -0.066 & 0.271 \\
\hline & $\mathrm{PC} 2_{\text {topo }}$ & -0.052 & 0.255 & -0.067 & 0.27 & 0.097 & 0.309 \\
\hline & PC 3 topo & $0.359^{*}$ & $0.959^{*}$ & $0.328^{*}$ & $0.92^{*}$ & 0.094 & 0.305 \\
\hline \multirow{5}{*}{ Namgyori } & $\mathrm{PC} 1_{\text {clim }}$ & -0.022 & 0.269 & 0.022 & 0.278 & -0.013 & 0.265 \\
\hline & $\mathrm{PC} 2_{\text {clim }}$ & -0.141 & 0.407 & -0.159 & 0.46 & $-0.362^{*}$ & $0.982^{*}$ \\
\hline & $\mathrm{PC}_{\text {topo }}$ & $-0.223^{*}$ & $0.672^{*}$ & $-0.190^{*}$ & $0.555^{*}$ & $-0.194^{*}$ & $0.592^{*}$ \\
\hline & $\mathrm{PC} 2_{\text {topo }}$ & -0.179 & 0.49 & $-0.197^{*}$ & $0.555^{*}$ & $0.256^{*}$ & $0.791^{*}$ \\
\hline & $\mathrm{PC} 3_{\text {topo }}$ & $0.215^{*}$ & $0.655^{*}$ & $0.178^{*}$ & $0.524^{*}$ & 0.129 & 0.389 \\
\hline
\end{tabular}

Beta coefficient is the standardized slope and the value indicates the relative importance for a factor in the model. Importance values are the posterior porbabilities over the set of hypotheses, representing the sum of the Akaike weights for each model containing the particular predictor in the model set. The factors that are included in the best model from all 31 possible models are highlighted with asterisk $\left({ }^{*}\right)$ and the best models are based on minimizing corrected Akaike information criterion among all possible models.
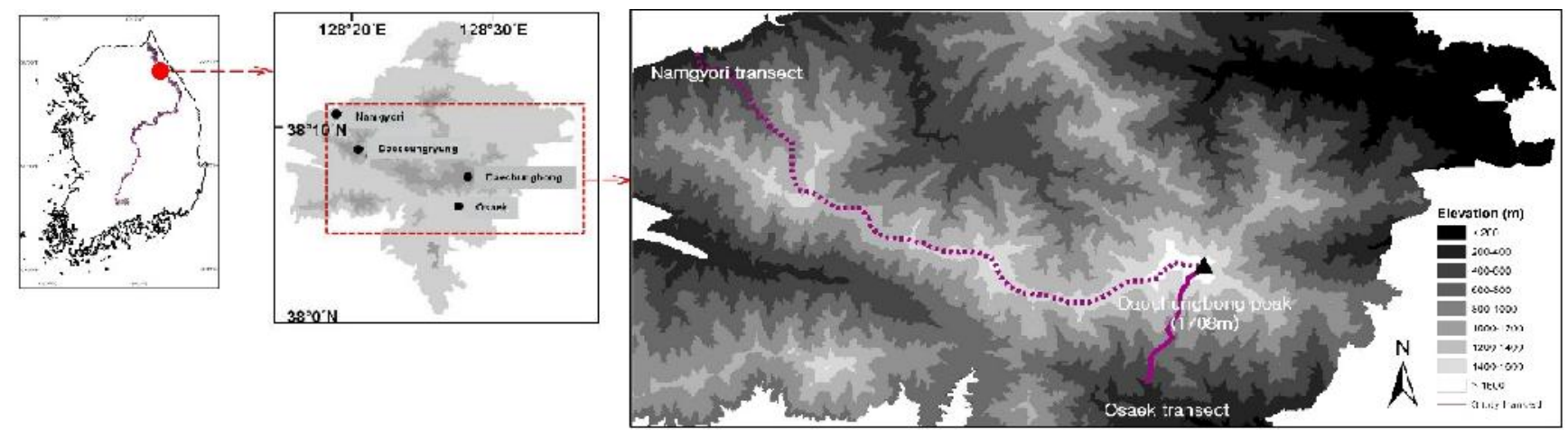

Fig. 1. Location and topography of the Mt. Seorak and the two study transects in South Korea. 


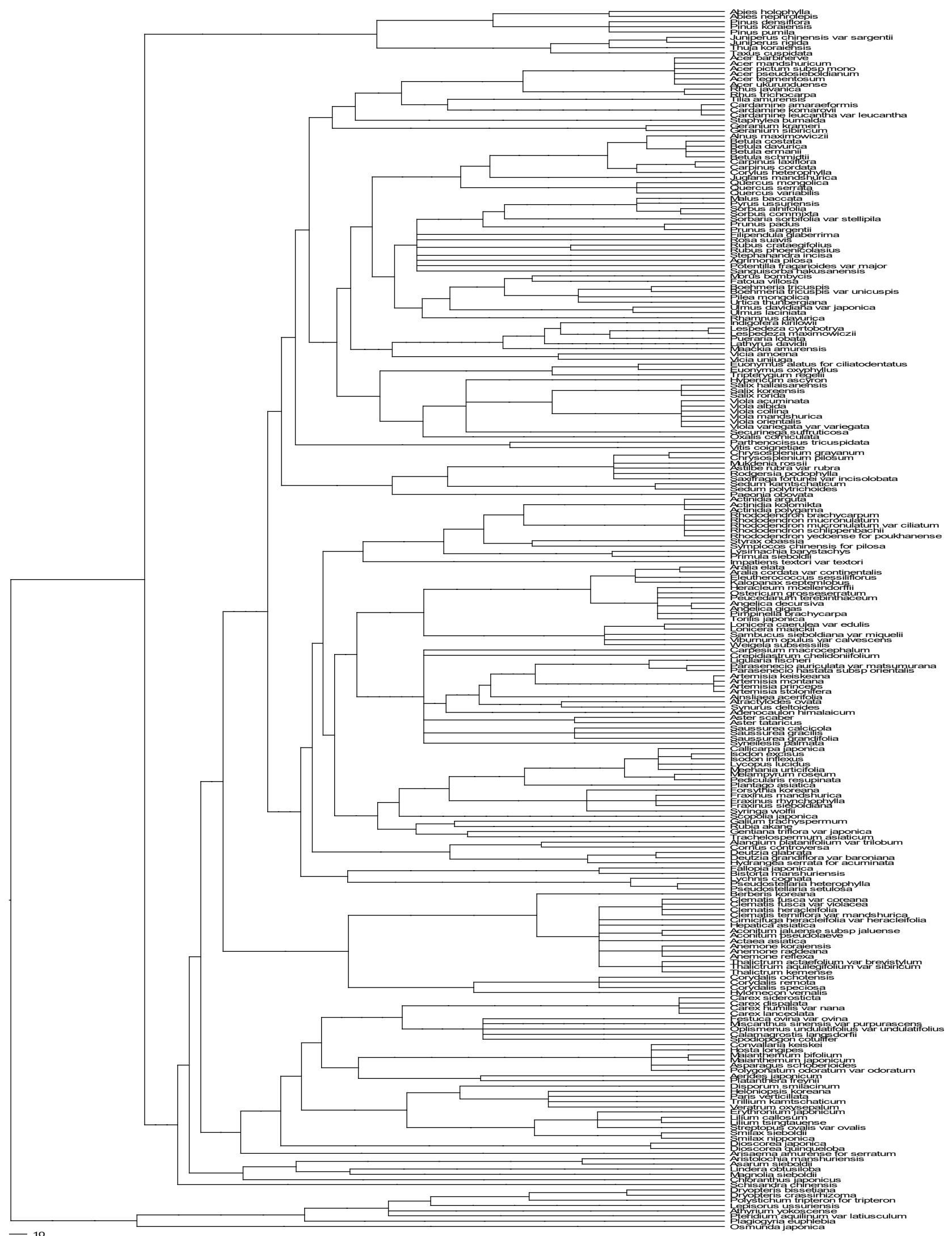

Fig. 2. Phylogenetic trees constructed in the present study for vascular plants from the two study transects in the Mt. Seorak. 
Osaek transect
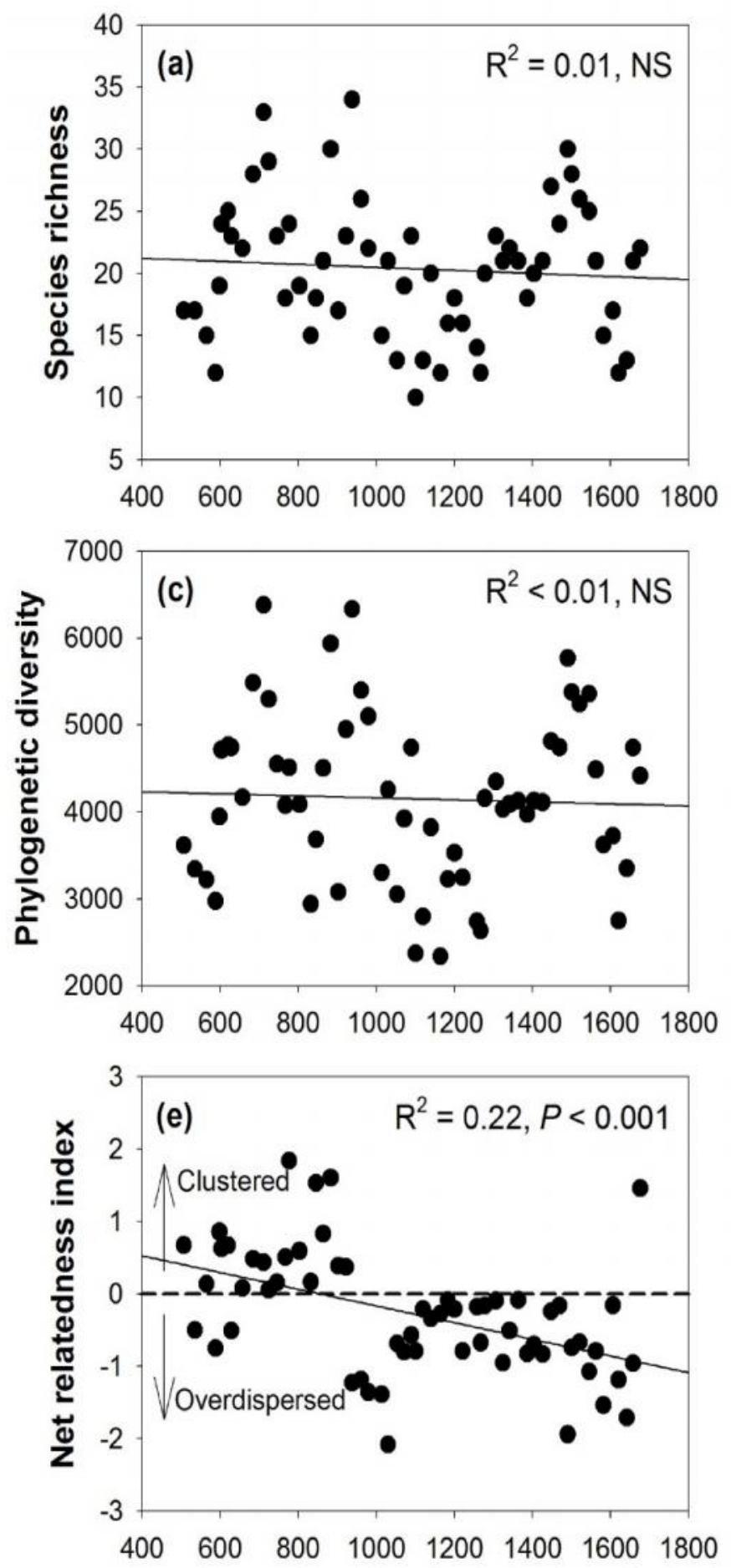

Elevation (m)
Namgyori transect
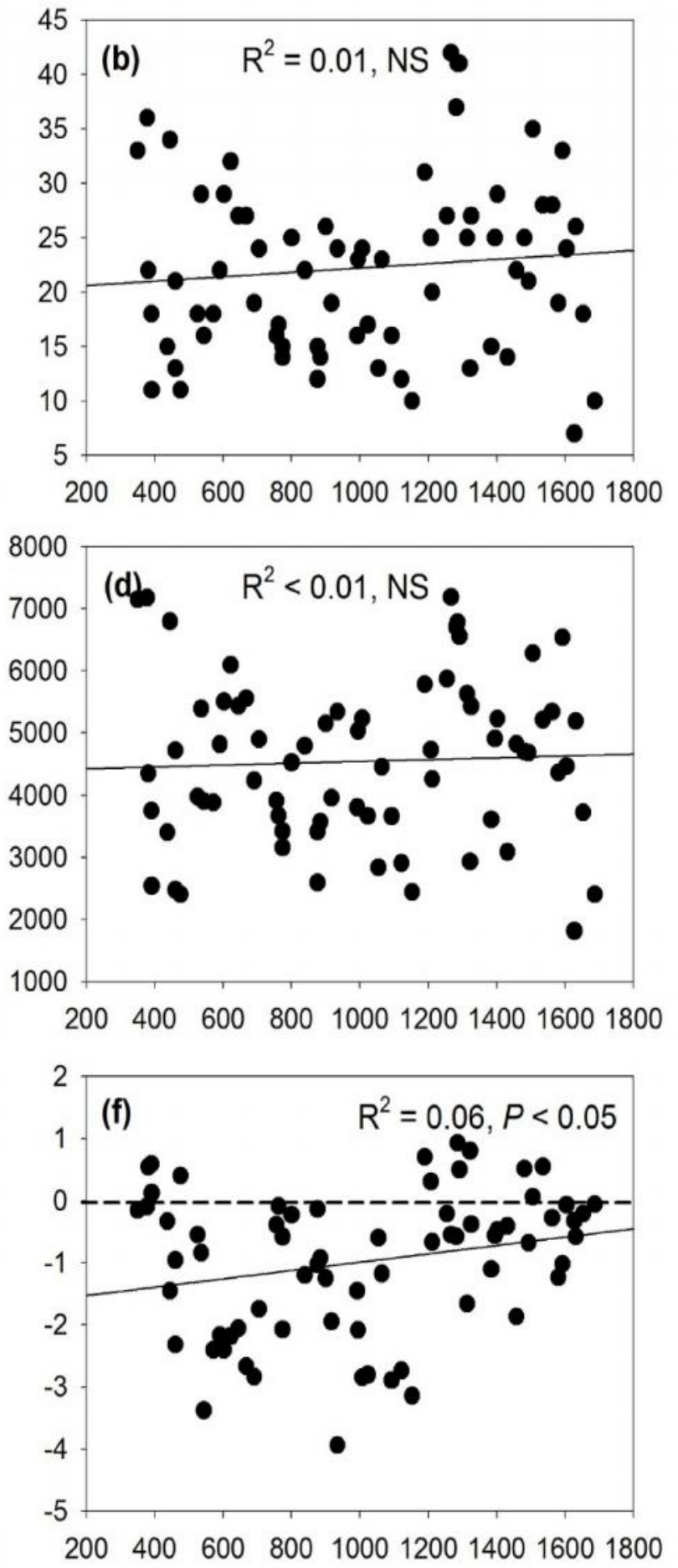

Elevation (m)

Fig 3. Relationships of (a-b) species richness, (c-d) Faith's phylogenetic diversity and (e-f) net relatedness index for vascular plants with elevation along the two study transects on the Mt. Seorak. 

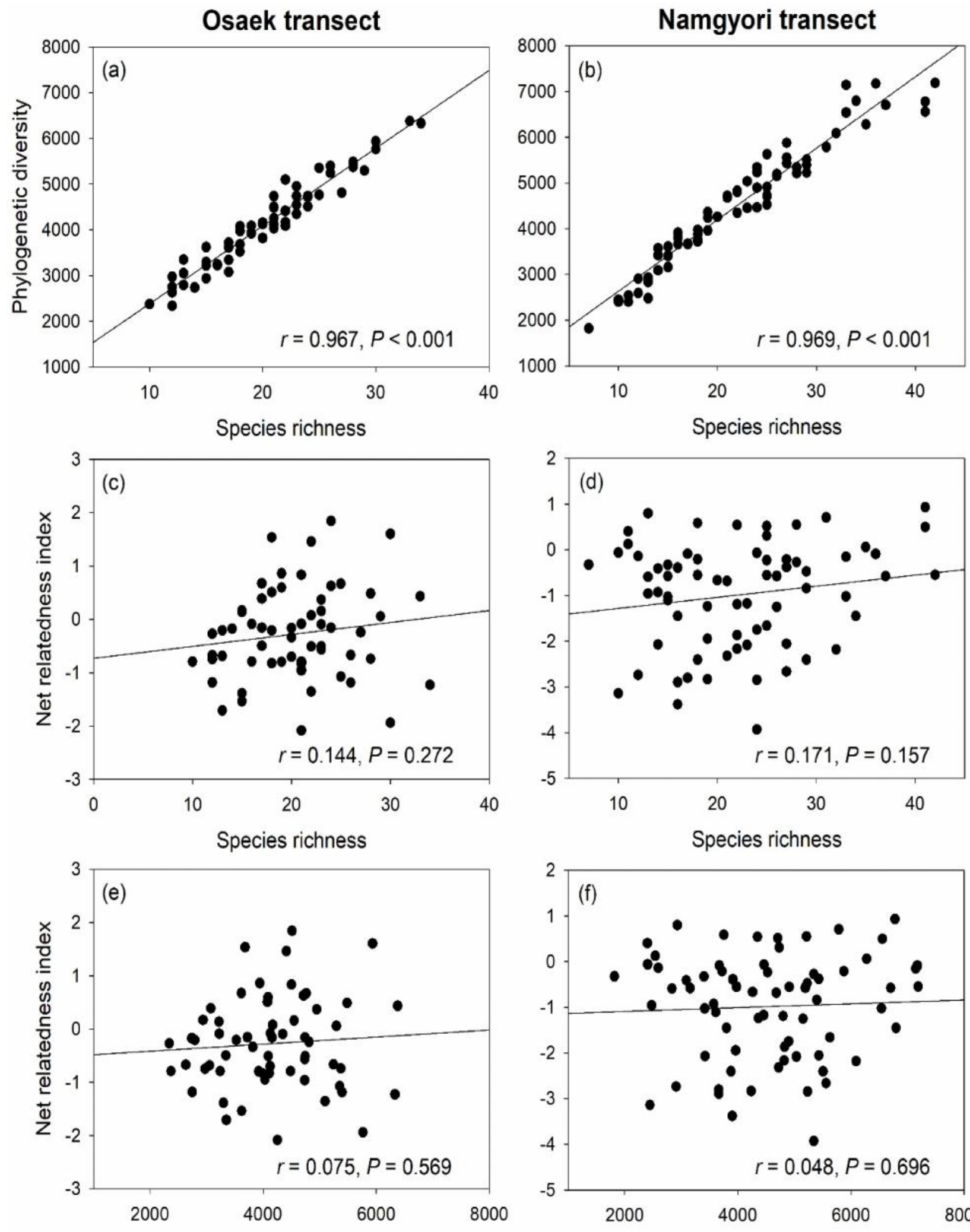

Phylogenetic diversity

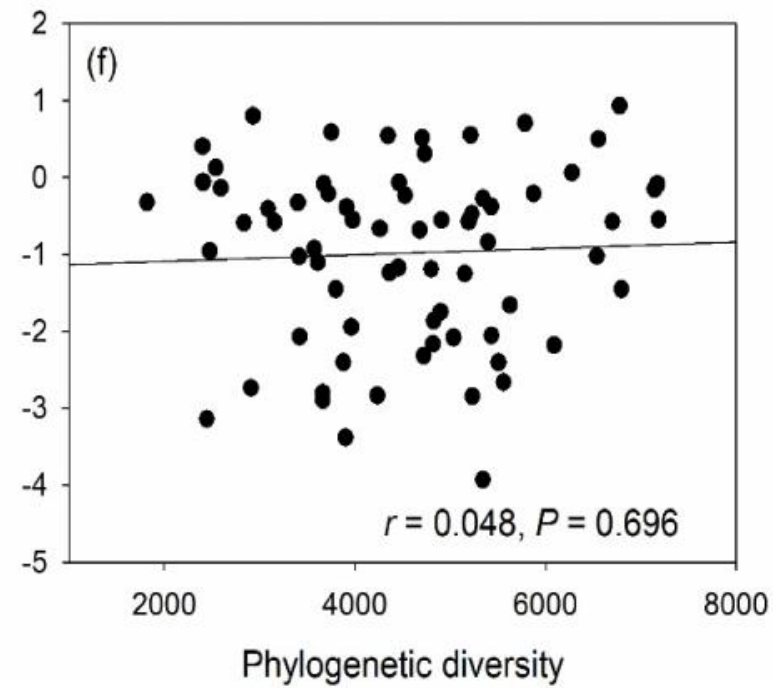

Fig. 4. Relationships between species richness, phylogenetic diversity and net relatedness index of vascular plants along the two study transects, Osaek and Namgrori, on the Mt. Seorak. 

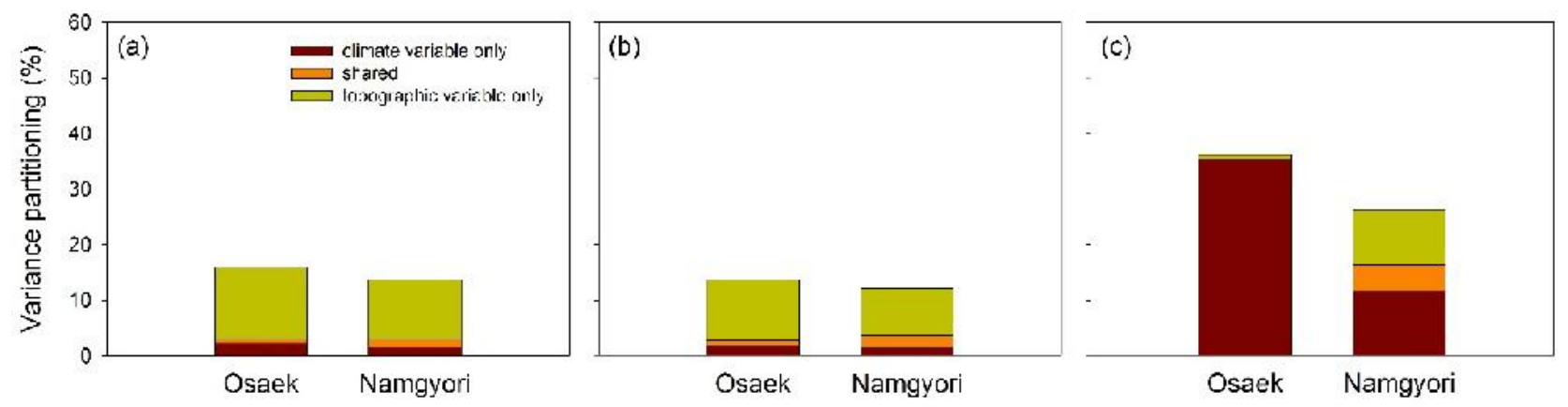

Fig. 5. Variation partitioning in (a) species richness, (b) Faith's phylogenetic diversity and (c) net relatedness index of vascular plants explained by climatic and topographic factors along the two study transects on the Mt. Seorak.

\section{DISCUSSION}

This study examined the elevational patterns and the drivers of plant diversity and phylogenetic structure at small spatial scale using field data along two transects on a Korean temperate forest. Primary localscale data is a crucial material for understanding of the within-domain diversity in geographic levels, whereas secondary large-scale data is important to interpret the tendency across spatial grains (Oommen and Shanker, 2005; Rahbek, 2005). Thus, this study has strength and benefit on examining diversity patterns, the structure of community assembly and the drivers related to an empirical data collected on local-scale levels.

For plant diversity patterns, although species richness and PD of vascular plants showed no relationships (or random fluctuation) with increasing elevation along the study transects, two diversity indices had same tendency and strong correlation. The results indicate the possibility of species richness as a proxy of PD. Indeed, many studies documented that species richness highly and significantly correlated with Faith's phylogenetic diversity (Bryant et al., 2008; Davies and Buckley, 2011; Li et al., 2015; Yang et al., 2015). And, in a previous extensive review study, Rahbek (2005) reported that unimodal elevation patterns were recorded approximately $50 \%$, approximately $25 \%$ were a monotonic decline and the remaining $25 \%$ of the gradients were other patterns. This study shows that the elevation patterns of vascular plants along the transects belong to other patterns (i.e., remaining $25 \%$ ) based on the Rahbek's study. This study also represents that if species richness can be used as a substitute of PD, the general types of elevation patterns in species diversity can be applied for PD. The key drivers for these diversity patterns such as species richness and phylogenetic diversity were topographic factors. In general, topographic factors are thought as crucial factors regulating local-scale diversity (Moeslund et al., 2013) and can produce a complex and various mosaic structures of substrates, hydrology and biogeochemistry (Bledsoe and Shear, 2000; Sharma et al., 2019). Furthermore, these factors formed by topography may also affect plant distribution patterns through environmental constraints on plant survival and growth and offer a various habitats, as well as buffering against environmental change (Moeslund et al., 2013).

In phylogenetic community structure analysis, the NRIs showed contrasting patterns between the two transects although the main drivers of the patterns were similar as climatic factors. The NRIs with increasing elevation showed monotonic decreasing and increasing patterns along the Osaek and Namgyori transects, respectively. These results indicate phylogenetic overdispersion for the Osaek transect and phylogenetic clustering for the Namgyori transect are major processes structuring community assemblies of vascular plants. According to niche-based deterministic theory, phylogenetic overdispersion is generally explained by biotic interactions such as competition and facilitation to structure community diversity (Bryant et al., 2008; Chun and Lee, 2019). Callaway et al. (2002) documented that these biotic interactions are crucial drivers in alpine plant community assembly, with a shift from competition at low elevations with less stressful environmental conditions to facilitation at high elevations with high environmental stress. Therefore, increased overdispersion at higher elevations suggests that the effect of facilitation on plant communities at high elevations is stronger than the effect of competition at low elevations (Bryant et al., 2008; Chun and Lee, 2019; Worthy et al., 2019). An alternative explanation is that the evolution of functional traits necessary to tolerate harsh environments at high elevations has occurred independently in distantly related species (i.e., convergent evolution in high alpine plants). In contrast to phylogenetic overdispersion, phylogenetic clustering is commonly explained as a result of environmental filtering (Webb et al., 2002; Bryant et al., 2008; Chun and Lee, 2018) because ecological traits are generally phylogenetically conserved (i.e., phylogenetic niche conservatism) and more closely related species are expected to be more ecologically similar (Webb et al., 
2002; Shooner et al., 2018). Therefore, this study supports the hypothesis that niche-based deterministic process such as environmental filtering and biotic interactions are a major underlying mechanism to form community structures in plant community assemblies along these transects, although the environmental drivers for phylogenetic community structures between the study transects may be somewhat different (Table 3). As main drivers to regulate phylogenetic community structure, climatic factors for the Osaek transect and climatic and topographic factors for the Namgyori transect were important (Table 3 and Fig. 5). Although climatic factors were simultaneously good predictors, the roles of climatic factors are likely to be different between the two transects. Along the Osaek transect, interspecific facilitation or the sorting of distantly related species with functional traits to tolerate harsh conditions (i.e., cold temperature) at high elevations may be influenced by climate. Moreover, only the restricted number of different lineages to avoid competition among similar lineages should be able to cause a lower NRI values and thus phylogenetic overdispersion occurs at high elevations (Pellissier et al., 2012; Yang et al., 2015; Zhou et al., 2018). On the other hand, along the Namgyori transect, climatic and topographic factors simultaneously may filter closely related species with the traits to cope with harsh climatic condition and topographic stress at high elevations and produce more phylogenetic clustering.

This study explored the patterns of plant diversity, phylogenetic community structure and their underlying mechanisms along two local elevation transects, the Osaek and Namgyori transects, using primary data in Mt. Seorak. Although the patterns of species richness and phylogenetic diversity showed no relationship with elevation along all transects, the main drivers of these diversity patterns were topographic factors. Two diversity indices showed same tendency and strong correlation along all study transects. The results support that the possibility of species richness as a proxy of phylogenetic diversity. Moreover, phylogenetic community structures showed phylogenetic overdispersion and phylogenetic clustering along the Osaek and Namgyori transects, respectively. These plant community structures were regulated by climatic factors on the Osaek transect and climatic and topographic factors for the Namgyori transect. These findings suggest that niche-based deterministic processes such as environmental filtering and interspecific interaction may be predominant in structuring community assembly of vascular plants along local elevation gradients and the specific processes for plant community structures may differ between nearby transects even in a same mountain ecosystem.

Conclusions: In conclusion, the main drivers to regulate the elevational patterns of species richness and phylogenetic diversity with increasing elevation were topographic factors along the study transects, Osaek and Namgyori transects, on the Mt Seorak, South Korea. Species richness can be used as a substitute of phylogenetic diversity but not net relatedness index as an index to measure phylogenetic community structure. Phylogenetic community structures were different between the study transects (i.e., phylogenetic overdispersion for for the Osaek and phylogenetic clustering for the Namgory transect) and these community structures were regulated by climatic factors on the Osaek transect and climatic and topographic factors for the Namgyori transect. These results suggest that niche-based deterministic processes such as environmental filtering and interspecific interaction are predominant in structuring community assembly of vascular plants along local elevation gradients on the study mountain.

Acknowledgments: We greatly thank Mr. Cho, SungYeol and Mr. Ahn, Hyo-Hyun for their full support and cooperation during the fieldwork and the data analysis in this study. Thanks are also due to Dr. Cho, Hyun-Je and Dr. Shin, Jun-Hwan for their encouragement and support. This study was carried out with the support of ' $R \& D$ Program for Forest Science Technology (Project No. 2019150C10-1923-0301)' provided by Korea Forest Service (Korea Forestry Promotion Institute).

\section{REFERENCES}

Bledsoe, B.P. and T.H. Shear (2000). Vegetation along hydrologic and edaphic gradients in a North Carolina coastal plain creek bottom and implications for restoration. Wetlands 20: 126147.

Braun-Blanquet, J. (1965). Plant Sociology. Hafner Publishing; New York (USA) $472 \mathrm{p}$.

Bryant, J.B., C. Lamanna, H. Morlon, A.J. Kerkhoff, B.J. Enquist and J.L. Green (2008). Microbes on mountainsides: contrasting elevational patterns of bacterial and plant diversity. Proceedings of the National Academy of Sciences USA 105: S11505-11511.

Burnham, K.P. and D.R. Anderson (2002). Model selection and inference: a practical informationtheoretic approach. 2nd Ed. Springer-Verlag; New York (USA). 488 p.

Cadotte, M.W., K. Carscadden and N. Mirotchnick (2011). Beyond species: functional diversity and the maintenance of ecological processes and services. J. Applied Ecology 48: 10791087.

Callaway, R.M., R.W. Brooker, P. Choler, Z. Kikvidze, C.J. Lortie, R. Michalet, L. Paolini, F.I. Pugnaire, B. Newingham, E.T. Aschehoug, C. 
Armas, D. Kikodze and B.J. Cook (2002). Positive interactions among alpine plants increase with stress. Nature 417: 844-848.

Chun, J.H. and C.B. Lee (2013). Assessing the effects of climate change on the geographic distribution of Pinus densiflora in Korea using Ecological Niche Model. Korean J. Agriculture and Forest Meteorology 15: 291-233. (In Korean)

Chun, J.H. and C.B. Lee (2018). Partitioning the regional and local drivers of phylogenetic and functional diversity along temperate elevational gradients on an East Asian peninsula. Scientific Reports 8: 2853 doi: 10.1038/s41598-018-21266-4

Chun, J.H. and C.B. Lee (2019). Temporal changes in species, phylogenetic, and functional diversity of temperate tree communities: insights from assembly patterns. Frontiers in Plant Science 10: 294 doi: 10.3389/fpls.2019.00294

Davies, T.J. and L.B. Buckley (2011). Phylogenetic diversity as a window into the evolutionary and biogeographic histories of present-day richness gradients for mammals. Philosophical Transactions of the Royal Society B 366: 24142425.

De Reu, J., J. Bourgeois, M. Bats, A. Zwertvaegher, V. Gelorini, P. De Smedt, W. Chu, M. Antrop, P. De Maeyer, P. Finke and M. Van Meirvenne (2013). Application of the topographic position index to heterogeneous landscapes. Geomorphology 186: 39-49.

Diniz-Filho, J.A.F., L.M. Bini and B.A. Hawkins (2003). Spatial autocorrelation and red herrings in geographical ecology. Global Ecology and Biogeography 12: 53-64.

Dreiss, L.M., K.R. Burgio, L.M. Cisneros, B.T. Klingbeil, B.D. Patterson, S.J. Presley and M.R. Willig. (2015). Taxonomic, functional and phylogenetic dimensions of rodent biodiversity along an extensive tropical elevational gradient. Ecography 38: 876-888.

Faith, D.P. (1992). Conservation evaluation and phylogenetic diversity. Biological Conservation 61: 1-10.

Gaston, K.J. (2000). Global patterns in biodiversity. Nature 405: 220-227.

Grau, O., J.A. Grytnes, H.J.B. Birks (2007). A comparison of altitudinal species richness patterns of bryophytes with other plant groups in Nepal, Central Himalaya. J. Biogeography 34: 1907-1915.

Grytnes, J.A. and O.R. Vetaas (2002). Species richness and altitude: a comparison between null models and interpolated plant species richness along the Himalayan altitudinal gradient, Nepal. American Naturalist 159: 294-304.
Grytnes, J.A., Heegaard, E. and P.G. Ihlen (2006). Species richness of vascular plants, bryophytes, and lichens along an altitudinal gradient in western Norway. Acta Oecologica 29: 241-246.

Jenness, J.S. (2004). Calculating landscape surface area from digital elevation models. Wildlife Society Bulletin 32: 829-839.

Jetz, W. and C. Rahbek (2002). Geographic range size and determinants of avian species richness. Science 297: 1548-1551.

Kembel, S.W. and S.P. Hubbell (2006). The phylogenetic structure of a neotropical forest tree community. Ecology 87: S86-99.

Kluge, J. and M. Kessler (2011). Phylogenetic diversity, trait diversity and niches: species assembly of ferns along a tropical elevational gradient. J. Biogeography 38: 394-405.

Kong, W.S. (2007). Biogeography of Korea plants. GeoBook Publishing; Seoul (Republic of Korea). 335 p.

Lee, C.B., J.H. Chun, H.K. Song and H.J. Cho (2013). Altitudinal patterns of plant species richness on the Baekdudaegan Mountains, South Korea: mid-domain effect, area, climate, and Rapoport's rule. Ecological Research 28: 67-79.

Legendre, P. (1993). Spatial autocorrelation: trouble or new paradiam? Ecology 85: 1659-1673.

Legendre, P. and L. Legendre (1998). Numerical ecology. 2nd Ed. Elsevier; Amsterdam (Netherland). 853 p.

Li, R., N.J.B. Kraft, H. Yu and H. Li (2015). Seed plant phylogenetic diversity and species richness in conservation planning within a global biodiversity hotspot in eastern Asia. Conservation Biology 29: 1552-1562.

Liew, T.S., M. Schilthuizen and M. Lakim (2010). The determinants of land snail diversity along a tropical elevational gradient: insularity, geometry and niches. J. Biogeography 37: 1071-1078.

McCain, C.M. (2009). Global analysis of bird elevational diversity. Global Ecology and Biogeography 18: 346-360.

Moeslund, J.E., L. Arge, P.K. Bøcher, T. Dalgaard and J.C. Svenning (2013). Topography as a driver of local terrestrial vascular plant diversity patterns. Nordic J. Botany 31: 129-144.

Oommen, M.A. and K. Shanker (2005). Elevational species richness patterns emerge from multiple local mechanisms in Himalayan woody plants. Ecology 86: 3039-3047.

Pellissier, L., N. Alvarez, A. Espíndola, J. Pottier, A. Dubuis, J.N. Pradervand and A. Guisan (2012). Phylogenetic alpha and beta diversities of butterfly communities correlated with climate in the western Swiss Alps. Ecography 35: 1-10. 
Rahbek, C. (2005). The role of spatial scale and the perception of large-scale species-richness patterns. Ecology Letters 8: 224-239.

Rowe, R.J. (2009). Environmental and geometric drivers of small mammal diversity along elevational gradients in Utah. Ecography 32: 411-422.

Sharma, N., M.D. Behera, A.P. Das and R.M. Panda (2019). Plant richness pattern in an elevational gradient in the Eastern Himalaya. Biodiversity and Conservation 28: 2085-2104.

Shooner, S., T.J. Davies, P. Saikia, J. Deka, S. Bharali, O.P. Tripathi, L. Singha, M.L. Khan and S. Dayanandan (2018). Phylogenetic diversity patterns in Himalayan forests reveal evidence for environmental filtering of distance lineages. Ecosphere 9: e02157. doi: 10.1002/ecs2.2157

Storch, D., R.G. Davies, S. Zajíček, C.D. Orme, V. Olson, G.H. Thomas, T.S. Ding, P.C. Rasmussen, R.S. Ridgely, P.M. Bennett, T.M. Blackburn, I.P. Owens and K.J. Gaston (2006). Energy, range dynamics and global species richness patterns: Reconciling mid-domain effects and environmental determinants of avian diversity. Ecology Letters 9: 1308-1320.

Swenson, N.G. (2011). The role of evolutionary processes in producing biodiversity patterns, and the interrelationships between taxonomic, functional and phylogenetic diversity. American J. Botany 98: 472-480.

Swenson, N.G., J.C. Stegen, S. Davies, D.L. Erickson, J. Forero-Montaña, A.H. Hurlbert, W.J. Kress, J. Thompson, M. Uriarte, S.J. Wright and J.K. Zimmerman. (2012). Temporal turnover in the composition of tropical tree communities: functional determinism and phylogenetic stochasticity. Ecology 93: 490-499.

Webb, C.O., D.D. Ackerly, M.A. McPeek and M.J. Donoghue (2002). Phylogenies and community ecology. Annual Review of Ecology and Systematics 33: 475-505.

Webb, C.O. and M.J. Donoghue (2005). Phylomatic: tree assembly for applied phylogenetics. Molecular Ecology Notes 5: 181-183.

Webb, C.O., D.D. Ackerly and S. Kembel (2008). Phylocom: software for the analysis of phylogenetic community structure and trait evolution. Bioinformatics 24: 2099-2101.

Wikstrom, N., V. Savolainen and M.W. Chase (2001). Evolution of angiosperms: calibrating the family tree. Proceedings of the Royal Society London B 268: 2211-2220.

Worthy, S.J., R.A.A. Paz, Á.J. Pérez, A. Reynolds, J. Cruse-Sanders, R. Valencia, J.A. Barone and K.S. Burgess (2019). Distribution and community assembly of trees along an Andean elevational gradient. Plants 8: 326. doi: $10.3390 /$ plants 8090326

Yang, J., N.G. Swenson, G. Zhang, X. Ci, M. Cao, L. Sha, J. Li, J.W.F. Slik and L. Lin (2015). Local-scale partitioning of functional and phylogenetic beta diversity in a tropical tree assemblage. Scientific Reports 5: 12731. doi: 10.1038/srep 12731

Zhou, Y., S. Chen, G. Hu, G. Mwachala, W. Yan and Q. Wang (2018). Species richness and phylogenetic diversity of seed plants across vegetation zones of Mount Kenya, East Africa. Ecology and Evolution 8:8930-8939. 